Goldschmidt 2021 Abstract

https://doi.org/10.7185/gold2021.7776

\section{Direct, Precise Measurements of Oxygen-17 Anomalies in CO2 Using VCOF-CRDS}

\author{
JUSTIN CHAILLOT ${ }^{1}$, SAMIR KASSI ${ }^{1}$, MATHIEU \\ CASADO $^{2}$, AMAELLE LANDAIS $^{3}$ AND MATHIEU \\ DAËRON $^{4}$ \\ ${ }^{1}$ Laboratoire Interdisciplinaire de Physique \\ ${ }^{2}$ Alfred Wegener Institute \\ ${ }^{3}$ LSCE - Institut Pierre Simon Laplace \\ ${ }^{4}$ Laboratoire des Sciences du Climat et de l'Environnement \\ Presenting Author: justin.chaillot@univ-grenoble-alpes.fr
}

Triple oxygen isotope analyses of $\mathrm{CO} 2$ are a challenge for mass spectrometers because of isobaric interference between $16 \mathrm{O} 13 \mathrm{C} 16 \mathrm{O}$ and $16 \mathrm{O} 12 \mathrm{C} 17 \mathrm{O}$. Using spectroscopic methods, each $\mathrm{CO} 2$ isotopologue is uniquely described by its distribution of masses and roto-vibrational frequencies, potentially providing simple, direct, non-destructive measurements of $\delta 13 \mathrm{C}, \delta 18 \mathrm{O}$ and $\Delta 17 \mathrm{O}$ on small samples of $\mathrm{CO} 2$. It remains technically challenging, however, to constrain istopologue abundances from infra-red absorption spectra with precision levels of $<10 \mathrm{ppm}$, as required by many geochemical applications. Here we report the latest results documenting the repeatability, linearity and accuracy of $\Delta 17 \mathrm{O}$ measurements by V-shaped Cavity Optical Feedback Cavity Ring-Down Spectroscopy (VCOF-CRDS), a novel technique combining the excellent absorption linearity of CRDS with state-of-the art spectral stability and selectivity [1,2].

By using different laser diodes, all locked to a single ultrastable V-shaped cavity, we are able to select optimal absorption lines to probe each isotopologue of interest. Our instrument currently performs simultaneous analyses of $\delta 13 \mathrm{C}, \delta 18 \mathrm{O}$ and $\delta 17 \mathrm{O}$ with external repeatabilities of $10 \mathrm{ppm}$ and $\Delta 17 \mathrm{O}$ at $8 \mathrm{ppm}$ by alternating 150 -s-long measurements between unknown samples and a working reference gas, with each unknown-tounknown cycle requiring $10 \mathrm{~min}$. Analyses of one pressurized tank of $\mathrm{CO} 2$ against another one over long time series display excellent $\Delta 17 \mathrm{O}$ stability $(\mathrm{SD}=7.6 \mathrm{ppm})$ at time scales exceeding $24 \mathrm{~h}$ (155 analyses). We will also report the results of our ongoing tests of linearity and accuracy, based on carbonate reference materials and $\mathrm{CO} 2$ isotopically equilibrated with independently-constrained waters with known $\triangle 17$ OVSMOW values ranging from -95 to $+32 \mathrm{ppm}$.

[1] T. Stoltmann, M. Casado, M. Daëron, A. Landais \& S. Kassi (2017). Direct, Precise Measurements of Isotopologue Abundance Ratios in $\mathrm{CO} 2$ Using Molecular Absorption Spectroscopy : Application to $\Delta 17 \mathrm{O}$. Analytical Chemistry. 10.1021/acs.analchem.7b02853

[2] S. Kassi, T. Stoltmann, M. Casado, M. Daëron \& A. Campargue (2018). Lamb dip CRDS of highly saturated transitions of water near $1.4 \mu \mathrm{m}$. The Journal of Chemical Physics. 10.1063/1.5010957
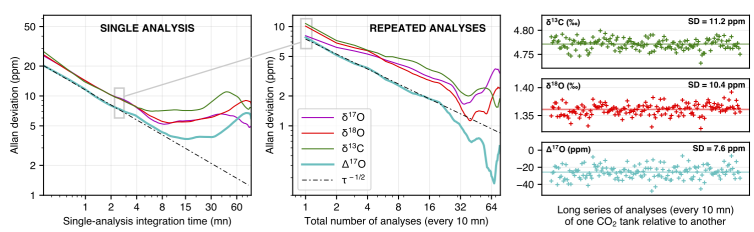

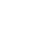

